\title{
Perspectives on gender parity in bioanalysis: an interview with Michael R Borenstein
}

Michael R Borenstein*,1

${ }^{1}$ School of Pharmacy, Department of Pharmaceutical Sciences, Temple University, 3307 N Broad St, Philadelphia, PA 19140, USA

*Author for correspondence: borenste@temple.edu

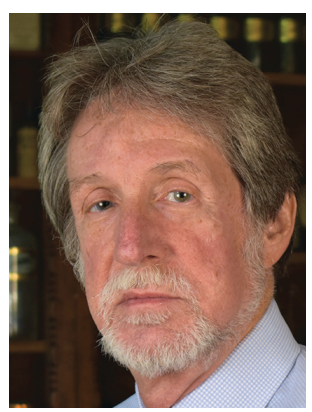

\section{Biography:}

MR Borenstein is Senior Associate Dean of Operations for Temple University School of Pharmacy, Associate Professor of Medicinal Chemistry, Director of the Office of Continuing Professional Education and Director of the Admissions Committee for the PharmD program. He formally served as Chair of the Department of Pharmaceutical Sciences. He is a registered pharmacist licensed to practice in Pennsylvania. His teaching responsibilities include biochemistry and medicinal chemistry. At the graduate level, he developed and taught pharmaceutical analysis and practical chromatography. His area of expertise and research involves the development of analytical techniques to investigate drug disposition in various biologic matrices and novel support materials for chromatography. He received a BA in liberal arts, a BS in pharmacy and a PhD in medicinal chemistry all from Temple University. He completed postdoctoral studies in neuropharmacology and neurochemistry at Hahnemann School of Medicine (now Drexel University) and at Temple University's Department of Chemistry.

Accepted for publication: 11 March 2019; Published online: 18 April 2019

\section{What advice would you give to young women hoping to embark on a career in the field?}

This is a particularly exciting time for women to begin their journey in a Sciences, Technology, Engineering, Maths (STEM) field. The social and political climate, both nationally and internationally, augurs well for women scientists. The conversation regarding gender parity is a front page issue and for the first time is a serious consideration in acceptance to institution of higher learning, as well as, industrial hiring. In my 32 years in academia, I have noticed in the last 5 years an increase in female applications and admissions to our graduate programs in pharmaceutical sciences. Every female graduate from our program has found meaningful and fulfilling careers in everything from the US FDA to Regulatory Affairs/Quality Assurance (RA/QA) to postdoctoral fellowships. It would be naive to think that all of the long-standing biases against women are gone but I believe we are witnessing a shift in the male-dominated scientific culture and now is the perfect time for women to pursue STEM career.

\section{How can mentors help women in their career development?}

Female mentors have a unique perspective that can encourage nascent women scientists. The trajectory from student to scientist is best illustrated by those who are established and successful. As a male adviser, I have always recommended to my female graduate students that they seek out advice from successful women regarding the challenges in the job market. To that end, our institution invites women scientists as guests lecturers and we always provide time for them to meet with students. At present, we actually have more female than male graduate students a situation that in no small part is due to the efforts of our female faculty members.

\section{How important it is to have a short-term and long-term goals in your career?}

This is a personal choice. Many scientists I have known, especially in the industrial setting, have told me they never had aspirations or a goal to be in a management track but being in the right place at the right time, seeing an opportunity, would act upon it. This is not to say that having goals is counterproductive but as Winston Churchill said "Success is not final, failure is not fatal: it is the courage to continue that counts." 
What advice would you give to women hoping to pursue senior-level scientific positions? Go for it! Make sure you have conferred with women currently or previously in these positions. Do not sell yourself short. The glass ceiling is still there but there are substantial cracks and the opportunities are there.

\section{What are the most valuable skill sets women/diversity bring to an organization?}

It is been my experience that women/diversity, in general, have a refined sense of time management. I would not go into the reasons for this, but it is something I have noticed over the years.

\section{What do you see as being the most effective solution to getting more women involved in STEM careers?}

It is extremely important to begin the process early. It is a well-known fact that the interest in STEM begins to decrease by adolescence in females. Thus, it is incumbent on our primary and high school educators to encourage and support female participation in math and science. There are many excellent examples of local school districts focusing on this dilemma. It is extremely important that role models reach out to teenage girls. Just about every professional and scientific organization has programs for young adults and elementary school children with an emphasis on girls. These programs are crucial in nurturing future women scientists.

\section{How do you think the scientific field could inspire the next generation of scientists to advocate gender parity?}

I believe this has already begun. Although some may perceive the current climate as a backlash to years of male dominance, I remain sanguine that the psychosocial changes happening now will continue and the rise in the number of women scientists will increase. It is true that at the highest echelons of industry, very few women are represented, however, I see positive movement in academia. I believe this will eventually and inexorably lead to more inspirational role models and more seats at the table for women.

Disclaimer

The opinions expressed in this interview are those of the interviewee and do not necessarily reflect the views of Future Science Group.

Financial \& competing interests disclosure

The author has no relevant affiliations or financial involvement with any organization or entity with a financial interest in or financial conflict with the subject matter or materials discussed in the manuscript. This includes employment, consultancies, honoraria, stock ownership or options, expert testimony, grants or patents received or pending, or royalties.

No writing assistance was utilized in the production of this manuscript. 